\title{
Bim, Bad and Bmf: intrinsically unstructured BH3-only proteins that undergo a localized conformational change upon binding to prosurvival Bcl-2 targets
}

\author{
MG Hinds ${ }^{1}$, C Smits ${ }^{2}$, R Fredericks-Short ${ }^{2}$, JM Risk ${ }^{2}$, M Bailey ${ }^{3}$, DCS Huang ${ }^{1}$ and CL Day ${ }^{\star 2}$
}

\begin{abstract}
All BH3-only proteins, key initiators of programmed cell death, interact tightly with multiple binding partners and have sequences of low complexity, properties that are the hallmark of intrinsically unstructured proteins (IUPs). We show, using spectroscopic methods, that the BH3-only proteins Bim, Bad and Bmf are unstructured in the absence of binding partners. Detailed sequence analyses are consistent with this observation and suggest that most BH3-only proteins are unstructured. When Bim binds and inactivates prosurvival proteins, most residues remain disordered, only the $\mathrm{BH} 3$ element becomes structured, and the short $\alpha$ helical molecular recognition element can be considered to behave as a 'bead on a string'. Coupled folding and binding is typical of many IUPs that have important signaling roles, such as BH3-only proteins, as the inherent structural plasticity favors interaction with multiple targets. This understanding offers promise for the development of BH3 mimetics, as multiple modes of binding are tolerated.

Cell Death and Differentiation (2007) 14, 128-136. doi:10.1038/sj.cdd.4401934; published online 28 April 2006
\end{abstract}

Bcl-2 family proteins are important regulators of cell fate. The opposing factions of this family integrate diverse death and survival signals, and regulate initiation of apoptosis in response to various stimuli. ${ }^{1}$ Family members that promote cell survival ( $\mathrm{Bcl}-2, \mathrm{Bcl}-\mathrm{x}_{\mathrm{L}}, \mathrm{Bcl}-\mathrm{w}, \mathrm{A} 1$ and $\left.\mathrm{Mcl}-1\right)$ contain up to four $\mathrm{Bcl}-2$ homology $(\mathrm{BH})$ domains in addition to a $\mathrm{C}$-terminal hydrophobic sequence that targets them to the cytoplasmic face of intracellular membranes, particularly the mitochondria. The proapoptotic family members are more diverse. Those with multiple $\mathrm{BH}$ domains such as Bax and Bak (often referred to as Bax-like) have a critical nonredundant role that results in mitochondrial membrane disruption, whereas those with a single $\mathrm{BH}$ domain, referred to as $\mathrm{BH}$-only molecules, appear to function as the key initiators of death. In a healthy cell, the BH3-only molecules are either repressed (e.g. Noxa, Puma) or are present in an inactive state (e.g. Bim, Bmf, Bad and Bid). ${ }^{2}$ Upon receipt of a death stimulus, BH3-only molecules are activated, allowing them to engage and inactivate prosurvival $\mathrm{Bcl}-2$ proteins. ${ }^{3}$ Interaction of $\mathrm{BH} 3$-only proteins with their prosurvival partners ultimately leads to oligomerization of Bax and Bak, and release of apoptogenic factors from the mitochondria.

Initiation of apoptosis is thus intimately associated with the ability of BH3-only proteins to bind their prosurvival counterparts. This interaction depends on the integrity of both the $\mathrm{BH} 3$ domain of $\mathrm{BH} 3-$ only proteins and their binding site, a surface exposed hydrophobic groove on prosurvival proteins. ${ }^{3}$ Structures of prosurvival proteins (CED-9 and $\mathrm{BCl}-\mathrm{x}_{\mathrm{L}}$ ) from Caenorhabdhitis elegans and mammals bound to $\mathrm{BH} 3$ domain peptides from proapoptotic proteins, have revealed the conserved nature of this interaction despite only a low level of shared sequence identity. ${ }^{4-7}$ Notably, the conserved leucine and aspartic acid residues of the LXXXGDE motif, which defines BH3-only proteins, make critical contacts with conserved residues in the hydrophobic binding groove. ${ }^{4}$ Comparison of the CED-9 and $\mathrm{BCl}-\mathrm{x}_{\mathrm{L}}$ structures, in the presence and absence of ligand, also suggests that flexibility is important for binding as complex formation is accompanied by local rearrangements within the binding groove, but not by appreciable conformational change of the prosurvival $\mathrm{Bcl}-2$ protein core. $^{4-7}$

Rearrangements of the ligand associated with binding have not been fully characterized. Most studies have focused on short peptides that span the BH3 domain-binding motif. When bound to their cognate targets, these peptides adopt an $\alpha$-helical conformation, ${ }^{4-7}$ although in isolation they are mainly random coil in conformation, ${ }^{5,8}$ suggesting that a structural transition is associated with binding. However, Petros et al. ${ }^{5}$ showed that in the case of $\mathrm{Bad} \mathrm{BH} 3$ peptides, there appeared to be a correlation between helical propensity and binding affinity for $\mathrm{Bcl}-\mathrm{x}_{\mathrm{L}}$. Other studies have focused on the $\mathrm{BH}$-only proteins Bid, which presents a complex picture, as full-length Bid has an $\alpha$-helical structure similar to that of the prosurvival $\mathrm{Bcl}-2$ proteins, and the $\mathrm{BH} 3$ domain is well defined. ${ }^{9,10}$ Activation of Bid differs from other $\mathrm{BH} 3$-only proteins in that it requires proteolysis followed by myristoylation. ${ }^{2}$ These events may trigger rearrangement and exposure of the $\mathrm{BH} 3$ domain, allowing Bid to bind and inactivate prosurvival

\footnotetext{
${ }^{1}$ The Walter and Eliza Hall Institute of Medical Research, Parkville, Australia; ${ }^{2}$ Biochemistry Department, University of Otago, Dunedin, New Zealand and ${ }^{3}$ Department of Biochemistry and Molecular Biology, The University of Melbourne, Parkville, Australia

${ }^{*}$ Corresponding author: CL Day, Department of Biochemistry, University of Otago, 710 Cumberland St, PO Box 56, Dunedin 9001, New Zealand;

E-mail catherine.day@stonebow.otago.ac.nz

Keywords: BH3-only; Bcl-2; intrinsically unstructured; molecular recognition

Abbreviations: $\mathrm{BH}, \mathrm{Bcl}-2$ homology; CDF, cumulative distribution frequency; IUP, intrinsically unstructured protein; TM, transmembrane; HSQC, heteronuclear single quantum coherence

Received 22.12.05; revised 17.2.06; accepted 08.3.06; Edited by JC Martinou; published online 28.4.06
} 
molecules. However, the sequence and functional diversity shown by the $\mathrm{BH}$-only proteins make Bid a poor model. ${ }^{2,11}$

Many molecules with key regulatory roles in cells belong to the class of proteins referred to as intrinsically unstructured proteins (IUPs)'. ${ }^{12}$ These proteins do not have a well-defined tertiary structure and commonly undergo a structural transition on binding their cognate partners. ${ }^{13}$ Such conformational plasticity is consistent with the observed properties of the $\mathrm{BH} 3$ domain peptides from $\mathrm{BH} 3-$ only proteins but it is not known, if like Bid, these peptides have a defined structure when in the context of the intact protein. Using a combined bioinformatic and experimental approach, we have characterized both the solution structure of the BH3-only protein Bim and the nature of the conformational change associated with binding. Our data suggest that Bim is a member of the intrinsically unstructured class of proteins, and that it undergoes a localized conformational change when it binds prosurvival molecules. At least some other BH3-only proteins, including Bmf and Bad, also appear to be largely unstructured, suggesting that the model developed for Bim reflects other $\mathrm{BH} 3-$ only proteins. Unstructured regions of proteins have been previously reported to promote binding diversity, ${ }^{13}$ and it seems likely that the unstructured nature of $\mathrm{BH}$-only molecules contributes to their ability to bind multiple partners. ${ }^{8}$

\section{Results}

Sequence analysis suggests that Bim is a disordered protein. Alternative splicing gives rise to numerous bim mRNA transcripts, ${ }^{14}$ although the three main splice variants in cells are $\mathrm{Bim}_{\mathrm{S}}, \mathrm{Bim}_{\mathrm{L}}$ and $\mathrm{Bim}_{\mathrm{EL}}{ }^{15}$ The distinct isoforms differ in size and have different apoptotic activity owing to the presence or absence of specific exons (Figure 1a). ${ }^{16}$ All three main splice variants contain the $\mathrm{BH} 3$ domain encoded by exon 8 that is required for binding to prosurvival proteins, and a predicted hydrophobic transmembrane (TM) region (exon 11). ${ }^{15}$ Exon 4, present in both $\mathrm{Bim}_{\mathrm{L}}$ and Bim $\mathrm{EL}_{\mathrm{L}}$, but not in $\mathrm{Bim}_{\mathrm{S}}$, encodes the dynein light chain (DLC)-binding motif required for interaction with DLC1. ${ }^{17}$ Bim $_{S}$, which is not negatively regulated by interaction with DLC1, is a more potent inducer of death than isoforms that contain exon 4. Sequences encoded by exon 3 are phosphorylated and

Figure 1 Sequence analysis of Bim predicts that it is largely unstructured. (a) The exonic structure of the three main expressed Bim protein isoforms is shown (exons are color coded and their number is indicated above). The relative position of the $\alpha$-helix and $\beta$-strand identified in complexes with $\mathrm{Bcl}-\mathrm{x}_{\mathrm{L}}$ and DLC1 are indicated. Sequence positions shown above the line refer to mouse Bim. (b) Net charge/ hydrophobicity plot of the three main Bim splice variants and the Bim protein used in subsequent experiments (Bim $\left.\Delta_{\llcorner} \mathrm{C} 27\right)$. The charge/hydrophobicity diagram is divided into two regions by a line $(-)$, which corresponds to the equation $\langle R\rangle=2.743\langle H\rangle-1.109$. Proteins on the left side of the diagram are predicted to be disordered, whereas those on the right are predicted to be ordered. ${ }^{20,21}$ The positions of the 0.045 boundaries are shown (---). (c) CDF plots for Bims (green), $\mathrm{Bim}_{\mathrm{L}}$ (blue) and Bim $\mathrm{EL}$ (red). The order-disorder boundary (black) is as reported previously. ${ }^{21}$ (d) DisEMBL predicts structural disorder for Bim $\mathrm{EL}_{\text {. The blue curve is }}$ the REMARK465 prediction and the red curve is the COILS prediction. ${ }^{23}$ The horizontal blue and red lines correspond to the random expectation level for each predictor $^{23}$ targets Bim $_{\mathrm{EL}}$ for proteosomal degradation. ${ }^{16}$ The function of exon 2, present in all Bim splice forms, ${ }^{14}$ is unknown, but it contains a conserved lysine and potential ubiquitylation site. $^{18}$

The structural data available for Bim is limited to peptide fragments bound to its targets. Liu et al. ${ }^{6}$ showed that a 33-residue peptide encoding the $\mathrm{BH} 3$ domain of Bim formed an $\alpha$-helix when bound to the hydrophobic groove of $\mathrm{Bcl}-\mathrm{x}_{\mathrm{L}}$. In contrast, a nine-residue peptide containing the short motif
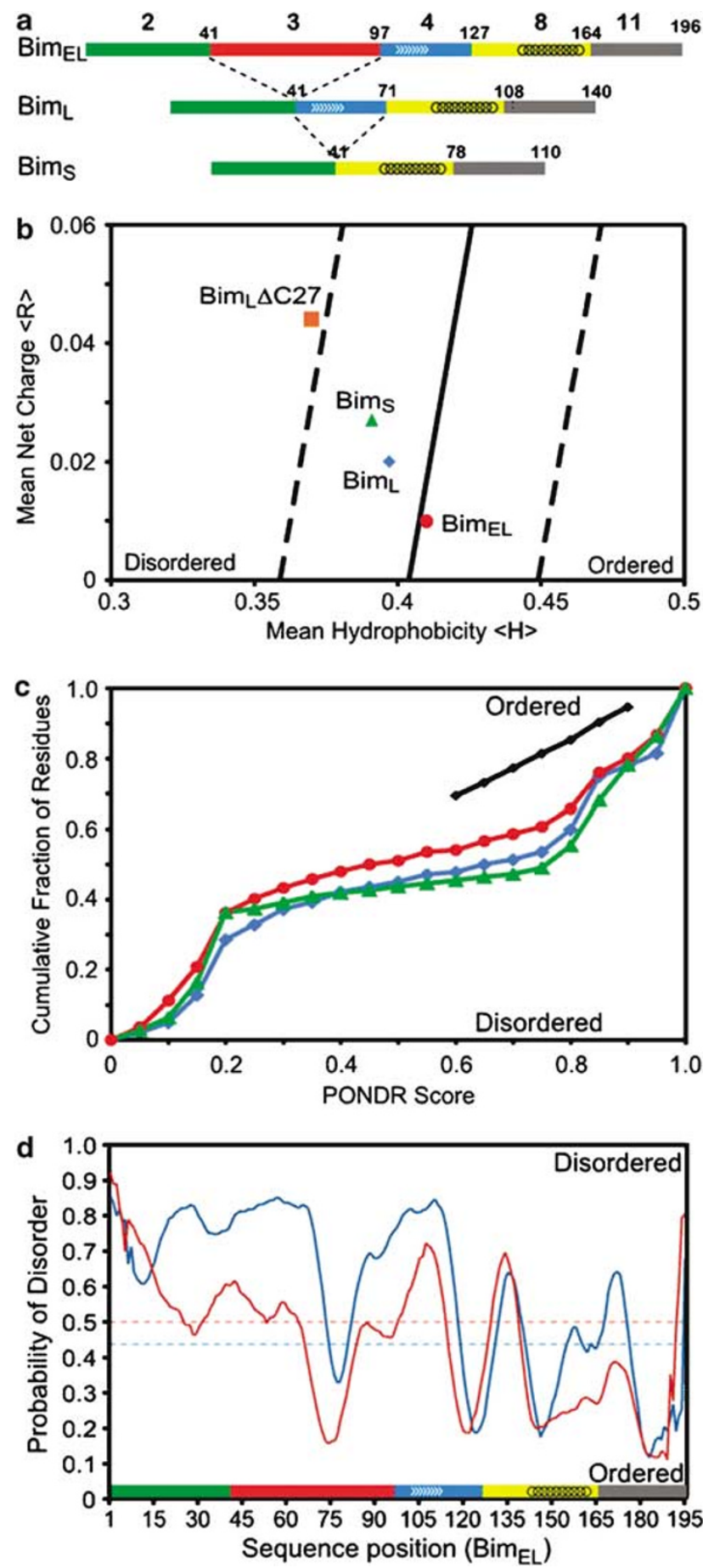

Cell Death and Differentiation 
required for binding to DLC forms a $\beta$-strand when bound to DLC1. ${ }^{19}$ In isolation, both peptides adopt a random coil conformation suggesting that a conformational change is associated with binding (MG Hinds and CL Day, unpublished). ${ }^{8}$ To determine whether the peptide studies reflect the structure of the equivalent regions within the context of fulllength Bim and to obtain a molecular understanding of protein conformations that tolerate extensive alternative splicing, a bioinformatic and structural analysis of full-length Bim was undertaken.

Initial analysis of the sequences of the three main Bim splice variants suggests that they have features typical of IUPS (Figure 1). When analyzed by the method of Uversky et al., ${ }^{20}$ which assesses intrinsic disorder based on the ratio between mean hydrophobicity and mean net charge, Bim $\mathrm{S}$ and Bim are predicted to be disordered, whereas Bim $_{\mathrm{EL}}$ lies on the boundary between the two states (Figure 1b). Cumulative distribution frequency plots (CDF) predict, with a high degree of confidence, that all three Bim splice variants are disordered (Figure 1c). In CDF plots, the predictors of natural disordered regions (PONDR) scores for each residue are represented as a histogram, allowing estimates of whole protein disorder to be made. Plots that fall below the seven-point boundary line between PONDR scores of 0.6 and 0.9 are likely to be disordered, as the majority of residues in these proteins have high PONDR scores. ${ }^{21}$ Analysis of 71 Arabidopsis thaliana proteins by both PONDR VL-XT and by nuclear magnetic resonance (NMR) (a ${ }^{1} \mathrm{H}-{ }^{15} \mathrm{~N}-\mathrm{HSQC}$, was recorded for each protein) revealed an $84 \%$ accuracy of predicting protein disorder. $^{22}$ To identify any localized regions of structure, Bim $_{E L}$ was also analyzed using DisEMBL. ${ }^{23}$ The DisEMBL predictor, which uses artificial neural networks that have been trained using data sets obtained from analysis of the protein databank, predicts that the $\mathrm{N}$-terminal region including exons 2 and 3 , and most of exon 4 is largely unstructured. Regions of order are predicted in the C-terminal exons, which contain the $\mathrm{BH} 3$ domain and the predicted TM region (Figure 1d), both of which are predicted to adopt an $\alpha$-helical conformation in certain conditions. Taken together, the sequence analyses suggest that when free in solution, multiple isoforms of Bim lack a well-defined structure, and that Bim is a member of the intrinsically unstructured class of proteins. IUPs commonly have an increased prevalence of phosphorylation sites ${ }^{24}$ and PEST (proline, glutamic acid, serine and threonine) sequences, ${ }^{25}$ and consistent with this Bim is phosphorylated and targeted for degradation by the proteasome in certain cell types. ${ }^{16}$

Bim lacks stable structure in solution. In order to directly investigate the structural properties of Bim, a number of expression constructs were generated. To obtain soluble protein, it was necessary to delete the 27 C-terminal hydrophobic residues ( $\Delta \mathrm{C} 27)$, which comprise most of exon 11 and are predicted to form a TM helix. ${ }^{15}$ Even with this deletion, only $B_{\mathrm{L}} \mathrm{L}_{\mathrm{L}}$ could be produced and purified in significant quantities. During purification, Bim ${ }_{\llcorner} \Delta \mathrm{C} 27$ was observed to be highly protease sensitive and behaved as a larger protein, migrating in sodium dodecyl sulfatepolyacrylamide gel electrophoresis (SDS-PAGE) as an approximately $16 \mathrm{kDa}$ protein and eluting from gel filtration columns with an apparent molecular weight of $\sim 25 \mathrm{kDa}$ (see Figure 3a). However, when analyzed by sedimentation velocity centrifugation and evaluated in terms of a single class of noninteracting solute, a molecular mass $\left(M_{\mathrm{r}}\right)$ of $13.2 \mathrm{kDa}$ was obtained (Figure $2 \mathrm{a}$ ). This is within $1 \%$ of $13.1 \mathrm{kDa}$, the calculated mass based on the amino-acid sequence, and indicates that $\operatorname{Bim}_{\mathrm{L}} \Delta \mathrm{C} 27$ exists as a monomer under the experimental conditions employed in the analytical ultracentrifuge. The slow migration on SDS-PAGE may be correlated with the high acidic content (16\%) of $\operatorname{Bim}_{\mathrm{L}} \Delta \mathrm{C} 27$ relative to globular proteins $(11.8 \%)$, as high negative charge is associated with both a larger Stokes radius for the protein detergent complex and a reduction in detergent binding. ${ }^{26}$ Elution as a larger protein when analyzed by size exclusion chromatography, and sensitivity to proteases, are both properties commonly observed for IUPs and suggest that $\operatorname{Bim}_{L} \Delta \mathrm{C} 27$ may be disordered in solution.

Circular dichroism (CD) and NMR spectroscopy were used to directly assess the secondary structure of $\operatorname{Bim}_{L} \Delta C 27$. Unstructured proteins give rise to $C D$ spectra with minima near $200 \mathrm{~nm}$ and some weak features (positive or negative) between 220 and $230 \mathrm{~nm}$. The presence of significant $\alpha$-helical structure is associated with minima at 222 and $208 \mathrm{~nm}$, and a positive signal at $200 \mathrm{~nm}$. The CD spectra obtained for $\mathrm{Bim}_{\mathrm{L}} \Delta \mathrm{C} 27$ over the range $5-65^{\circ} \mathrm{C}$ is characteristic of an unstructured protein, although the slight inflection near $222 \mathrm{~nm}$ may indicate some residual $\alpha$-helical structure, but this is not enhanced at lower temperatures as seen for some proteins (Figure $2 b$ ). ${ }^{27}$ Analysis of NMR spectra for Bim ${ }_{L} \Delta \mathrm{C} 27$ support this conclusion (Figure 2c). In the ${ }^{1} \mathrm{H}-{ }^{15} \mathrm{~N}-\mathrm{HSQC}$ spectrum (Figure $2 \mathrm{c}$ ), the backbone amide resonances fall between 8.0 and 8.5 p.p.m., and there is little dispersion in the aliphatic region in the $1 \mathrm{D}^{1} \mathrm{H}$ NMR spectrum (data not shown). The sharp resonances and lack of chemical shift dispersion reflect the intrinsic mobility and lack of long-range order in $\operatorname{Bim}_{L} \Delta \mathrm{C} 27$. The absence of stable tertiary structure is supported by the complete absence of any $\mathrm{HN}-\mathrm{HN}$ cross peaks in both proton 2D NOESY and a three-dimensional (3D) ${ }^{15} \mathrm{~N}$-NOESY spectra (data not shown). In heteronuclear $\left\{{ }^{1} \mathrm{H}\right\}{ }^{15} \mathrm{~N}$, NOEs spectra, most of the resonances were of negative intensity (data not shown), indicating mobility on the ps-ns time scale, features typical of IUPs. ${ }^{28}$ Bim $_{\mathrm{L}} \Delta \mathrm{C} 27$ contains a large number of proline residues (14 of 118 residues), and cis-trans isomerization about the proline amide bond, tolerated by unstructured proteins, probably accounts for the heterogeneity seen in the HSQC spectrum. Together, the CD and NMR data indicate that bacterially expressed $\operatorname{Bim}_{L} \Delta C 27$ is largely unstructured. Bim $\mathrm{L}_{\mathrm{L}}$ purified from insect Sf-9 cells was also susceptible to proteolysis, suggesting that this protein was unfolded. ${ }^{6}$ In both cases, the C-terminal putative TM region of Bim has been deleted, but it seems unlikely that the presence of the C-terminal residues would result in a compact globular structure, instead, as predicted based on sequence analysis (Figure 1), the major Bim isoforms are likely to be unstructured in solution.

Bim undergoes a limited structural transition in the presence of prosurvival molecules. Many IUPs undergo a structural transition upon binding to interacting molecules. $^{12,13}$ Bim binds tightly to all prosurvival proteins ${ }^{8}$ 
a

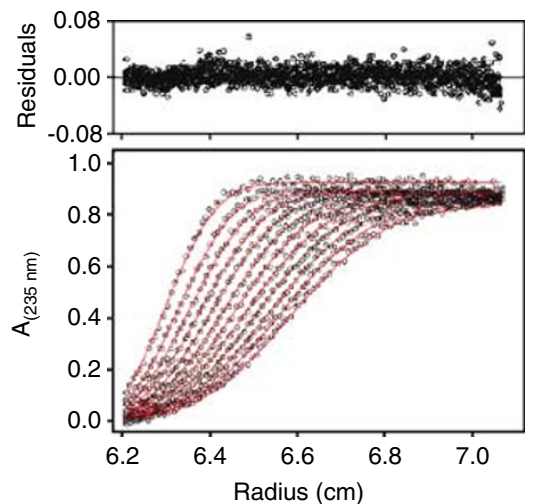

b

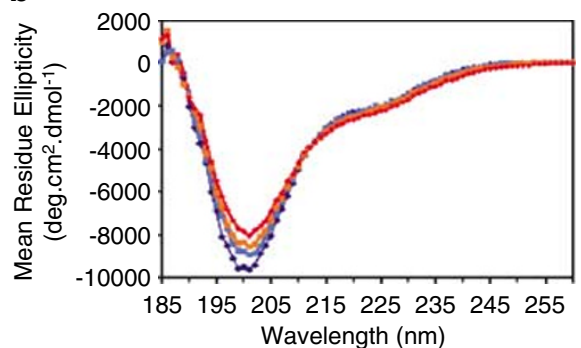

c

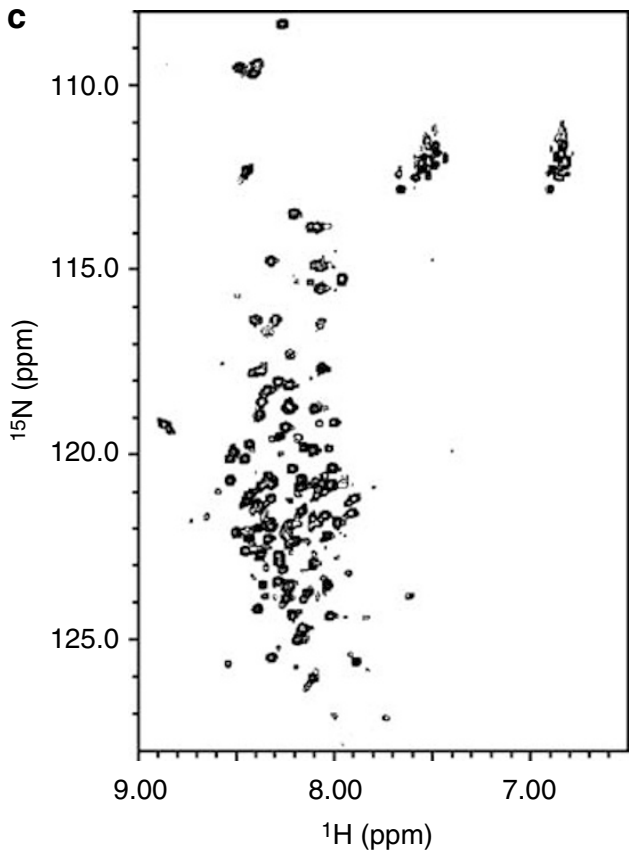

Figure $2 \operatorname{Bim}_{\mathrm{L}} \Delta \mathrm{C} 27$ is unstructured. (a) Analytical ultracentrifugation analysis of $\operatorname{Bim}_{\mathrm{L}} \Delta \mathrm{C} 27$. Data acquisition and analyses were carried out as described. The circles represent the radial scans used in the analysis $(15-50)$. For clarity, every third data set is shown. The continuous red lines represent the best fit of the data to the Lamm equation $(\mathrm{rmsd}=0.010)$. The values of the parameters recovered from the analysis were $c=0.94, M_{\mathrm{r}}=13200(12600-14000)$ and $S=1.60(1.56-1.63)$, where the numbers in parentheses represent $95 \%$ confidence limits. The distribution of unweighted residuals is shown above the main figure. (b) Far-UV CD spectrum of recombinant $\operatorname{Bim}_{\mathrm{L}} \Delta \mathrm{C} 27$ at $5,25,45$ and $65^{\circ} \mathrm{C}$ recorded in $20 \mathrm{~mm}$ sodium phosphate $\mathrm{pH}$ 6.7. (c) ${ }^{1} \mathrm{H}-{ }^{15} \mathrm{~N}$-HSQC spectra of ${ }^{15} \mathrm{~N}$-labeled Bim $\mathrm{L} \Delta \mathrm{C} 27$ recorded at $25^{\circ} \mathrm{C}$

and residues 85-113 (mouse $B_{\mathrm{L}} \mathrm{L}$ numbering), which include the BH3 domain, have been shown to form an $\alpha$-helix when bound to $\mathrm{Bcl}_{\mathrm{L}} \mathrm{x}^{6}$ As $\mathrm{Bim}_{\mathrm{L}} \Delta \mathrm{C} 27$ is largely unstructured in solution, a structural transition of at least the BH3 domain was expected upon binding prosurvival molecules. Gel filtration chromatography was used to characterize the complex formed between $\mathrm{Bcl}-\mathrm{W}$ and Bim (Figure 3a). When separated on a Superdex 200 column, $\mathrm{Bim}_{\mathrm{L}} \Delta \mathrm{C} 27$ behaved as a large protein as commonly observed for IUPs, and had an apparent molecular mass of $26.7 \mathrm{kDa}$ (calculated mass of $13.1 \mathrm{kDa}$ ), whereas the apparent mass for $\mathrm{Bcl}-\mathrm{w} \Delta \mathrm{C} 10$ was $17.1 \mathrm{kDa}$ (calculated mass of $18.3 \mathrm{kDa}$ ). When equimolar amounts of the two proteins were mixed before chromatography, they eluted together with an apparent molecular mass of $44.4 \mathrm{kDa}$ (Figure 3a, lower panel), close to the calculated $M_{\mathrm{r}}$ of $43.8 \mathrm{kDa}$ based on the apparent masses of the individual proteins, but larger than the predicted heterodimer molecular weight of $31.4 \mathrm{kDa}$. This suggested that, like Bim alone, the complex did not have a compact structure.

Partial proteolysis experiments were used to further evaluate the conformational changes associated with complex formation. When treated with trypsin, $\operatorname{Bim}_{\llcorner} \Delta \mathrm{C} 27$ was rapidly degraded to small peptides (Figure $3 \mathrm{~b}$, lanes 3 and 4 ), whereas Bcl-w was relatively resistant although after $60 \mathrm{~min}$ digestion, several proteolytic fragments appeared (Figure $3 \mathrm{~b}$, lanes 6 and 7). When Bcl-w $\Delta \mathrm{C} 10$ and $\operatorname{Bim}_{\llcorner} \Delta \mathrm{C} 27$ were mixed before trypsin digestion, a different proteolytic profile was obtained (Figure 3b, lanes 8 and 9). Mass spectrometry analysis of the peptide mixtures revealed changes consistent with complex formation. Notably, a peptide arising from proteolysis after R59 (helix 2-3 loop) and R78 (N-terminal of helix 4) in Bcl-w was no longer apparent, although a new peptide of $4621 \mathrm{kDa}$ was detected. The mass of the new peptide corresponds to that expected for a peptide derived from the $\mathrm{C}$-terminus of $\mathrm{Bim}_{\llcorner} \Delta \mathrm{C} 27$ (sequence shown at the bottom of Figure $3 b$ ). This peptide includes the $\mathrm{BH} 3$ domain and suggests that interaction with the hydrophobic binding groove protects the $\mathrm{BH} 3$ domain and the hydrophobic groove of Bcl-w from proteolysis. The Bim BH3 peptide was not detected when $\operatorname{Bim}_{\llcorner} \Delta \mathrm{C} 27$ was digested alone, but a similar peptide was found in the crystals of $\mathrm{Bcl}-\mathrm{x}_{\mathrm{L}} / \mathrm{Bim}$ where the $\mathrm{Bim}$ protein had undergone nonspecific proteolysis. ${ }^{6}$ Proteolysis of the $\mathrm{N}$-terminus of Bim was not affected by the presence of Bcl-w. Together, these results suggest that Bim remains largely unstructured in the presence of prosurvival proteins and that only a limited conformational change of just the $\mathrm{BH} 3$ domain is associated with binding.

To further investigate the nature of the structural transition associated with binding of Bim to Bcl-w, CD and NMR methods were used. A localized conformational change is supported by comparison of the ${ }^{1} \mathrm{H}-{ }^{15} \mathrm{~N}-\mathrm{HSQC}$ spectra for ${ }^{15} \mathrm{~N}$-labeled $\mathrm{Bim}_{\llcorner} \Delta \mathrm{C} 27$ in the presence and absence of $\mathrm{Bcl}-\mathrm{W}$ (Figure 3c). Notably, although addition of Bcl-w results in the appearance of a number of new peaks, the majority of peaks have the same position in both spectra suggesting that the structure of many residues in $\operatorname{Bim}_{L} \Delta \mathrm{C} 27$ is not altered by the presence of $\mathrm{Bcl}-\mathrm{w}$. The new peaks in the ${ }^{15} \mathrm{~N}-\mathrm{Bim}_{\llcorner} \Delta \mathrm{C} 27 / \mathrm{Bcl}-$ $\mathrm{w} \Delta \mathrm{C} 10$ complex spectra primarily arise from interaction of the $\mathrm{BH} 3$ domain with $\mathrm{Bcl}-\mathrm{w}$ as addition of $\mathrm{Bcl}-\mathrm{w} \Delta \mathrm{C} 10$ to 


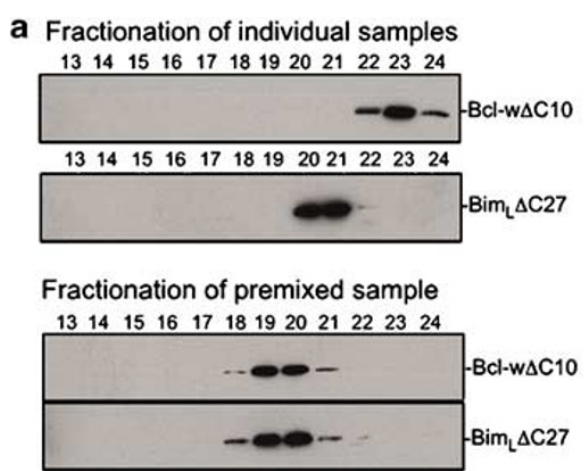

C

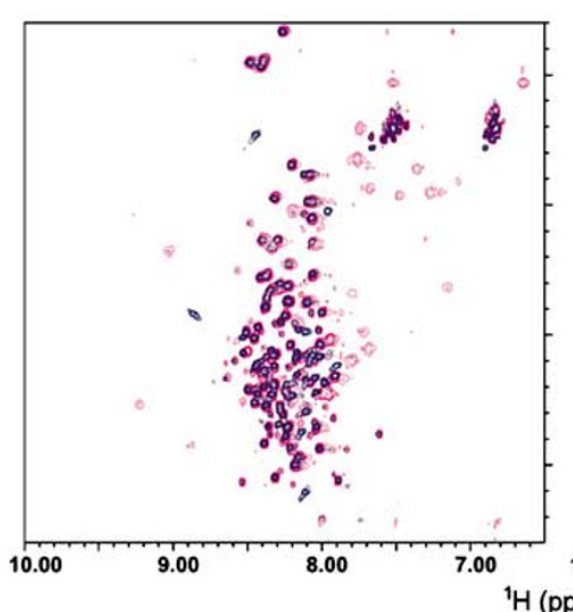

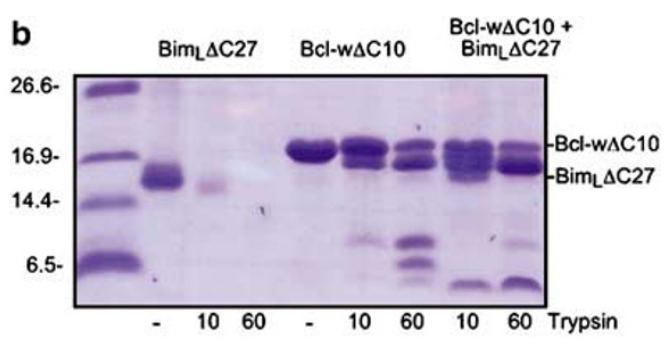

QSQEEPEDLRPEIRIAQELRRIGDEFNETYTRRVFAND

d
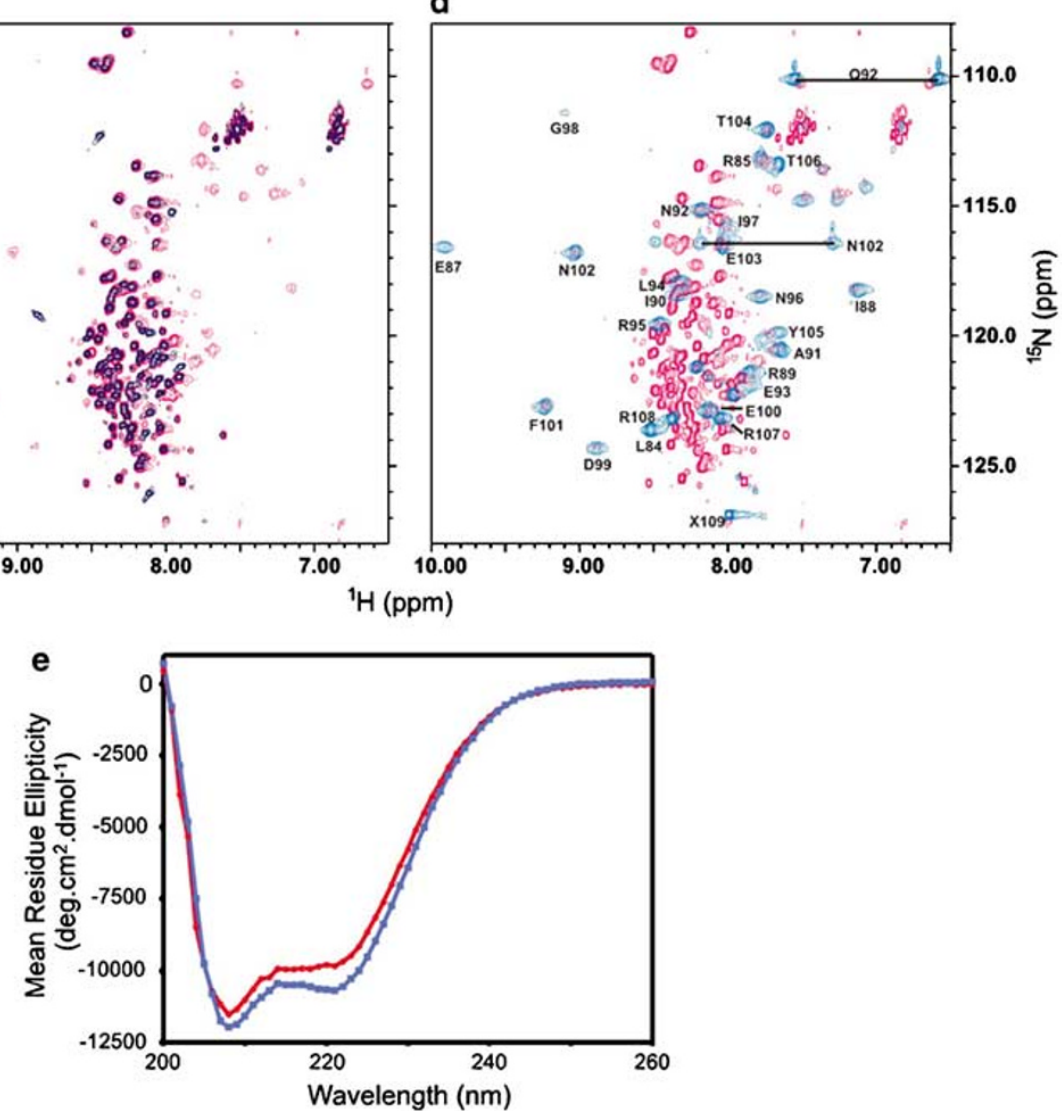

Figure 3 Interaction of $B \mathrm{Bm}_{\llcorner} \Delta \mathrm{C} 27$ with prosurvival $\mathrm{Bcl}-2$ molecules is associated with a localized conformational change. (a) Bim $\triangle \mathrm{C} 27$ and $\mathrm{Bcl}$-w $\Delta \mathrm{C} 10 \mathrm{copurify}$ when analyzed by gel filtration chromatography. $\operatorname{Bim}_{\mathrm{L}} \Delta \mathrm{C} 27$ and $\mathrm{Bcl}-\mathrm{w} \Delta \mathrm{C} 10$ were individually separated on an $\mathrm{S} 200$ column, and then an approximately equimolar mixture of the two proteins was separated. The indicated fractions were separated by SDS-PAGE and the proteins detected by Western blotting. (b) Purified Bim $\triangle \mathrm{C} 27$ and Bcl-w $\Delta \mathrm{C} 10$ were treated with trypsin for the indicated times, either alone (lanes 2, 3, 5 and 6) or following mixing (lanes 7 and 8 ). The sequence of the Bim peptide identified in lane 8 but not in lane 3 is shown below. (c) ${ }^{1} \mathrm{H}-{ }^{15} \mathrm{~N}$-HSQC spectra of ${ }^{15} \mathrm{~N}$-labelled Bim $\mathrm{L} \Delta \mathrm{C} 27$ in the absence (blue) and presence (pink) of unlabelled Bcl-w $\Delta \mathrm{C} 10$. (d) ${ }^{1} \mathrm{H}-{ }^{15} \mathrm{~N}-\mathrm{HSQC}$ spectra of ${ }^{15} \mathrm{~N}$-labelled BimBH3 (blue) and ${ }^{15} \mathrm{~N}$-labelled Bim $\triangle \mathrm{C} 27$ (pink) both in the presence of excess unlabelled Bcl-w $\Delta \mathrm{C} 10$. The assignments for the BimBH3 peptide are indicated. (e) Equimolar amounts of $B i m_{L} \Delta C 27$ and $B c l-w \Delta C 27$ and $B c l-w \Delta C 37$ were analyzed in a split mixing cuvette by $C D$ spectroscopy. The signals before mixing (red) and after mixing (blue) are shown

\begin{abstract}
${ }^{15} \mathrm{~N}$-labeled BimBH3 (a peptide including residues $83-108$ of mouse $B i m_{L}$ ) results in similar shifts (Figure $3 d$ ). The coincidence of the shifted peaks in the two complex spectra suggests that the $\mathrm{BimBH} 3$ peptide contains the full binding site found in $\operatorname{Bim}_{\llcorner} \Delta C 27$. The few differences seen are likely due to end effects. The comparable binding constants observed for Bcl-w binding to $\operatorname{Bim}_{\llcorner} \Delta \mathrm{C} 27$ protein $(32 \mathrm{nM})$ and the $\mathrm{BimBH} 3$ peptide $(22 \mathrm{nM})^{29}$ supports this conclusion.
\end{abstract}

When the $\mathrm{BH} 3$ domain of Bim binds to $\mathrm{Bcl}-\mathrm{x}_{\mathrm{L}}$, it adopts a helical conformation with contacts to residues in the hydrophobic groove. ${ }^{6}$ The $B H 3$ domain of $\operatorname{Bim}_{\llcorner} \Delta \mathrm{C} 27$ is likely to adopt a similar conformation when it binds to $\mathrm{Bcl}-\mathrm{w}$, as a small increase in helicity occurs after mixing equimolar amounts of $\mathrm{Bcl}-\mathrm{w}$ and $\mathrm{Bim}_{\llcorner} \Delta \mathrm{C} 27$ (Figure $3 \mathrm{e}$ ). Bcl-w $\Delta \mathrm{C} 37$ was used in this experiment as the C-terminal residues of $\mathrm{Bcl}-\mathrm{w}$, become unstructured upon complex formation ${ }^{30}$ and mask the $C D$ 
signal owing to helix formation of the ligand. Deletion of the $\mathrm{C}$ terminal residues does not affect binding as they are disordered and do not contact the peptide as evidenced by the absence of NOEs between the $\mathrm{Bim} \mathrm{BH} 3$ domain and the $\mathrm{C}$-terminal residues of Bcl-w $\Delta \mathrm{C} 10$ (data not shown). Consistent with these results Denisov et al. ${ }^{31}$ recently reported a similar structure for the $\mathrm{C}$-terminal residues of $\mathrm{Bcl}-\mathrm{w}$ when a Bid $\mathrm{BH} 3$ peptide is bound.

Collectively, these data suggest that Bim is a member of the intrinsically unstructured class of proteins that undergo a localized conformational change, involving helix formation of the contact residues in the $\mathrm{BH} 3$ domain, upon binding to its partner protein. Residues outside the $\mathrm{BH} 3$ domain contribute little to binding and have the same conformation in the presence and absence of prosurvival proteins.

Bad and Bmf are also largely unstructured in solution. Comparable $\mathrm{BH} 3$ domain peptides from all $\mathrm{BH} 3-$ only molecules have been shown to be unstructured when studied in isolation. $^{5,8}$ In the case of Bid, these same residues are ordered and have a distinct structure within the context of the full-length protein..$^{9,10}$ In contrast, we have shown that Bim does not have a well-defined structure and that the $\mathrm{Bim} \mathrm{BH} 3$ domain is unstructured. Our data strongly suggest that coupled folding and binding occur when the $\mathrm{BH} 3$ domain of Bim interacts with prosurvival proteins. To determine which model best represents other BH3-only proteins, we analyzed the sequence of all mouse BH3-only proteins using several predictors of disorder. Analysis based on mean hydrophobicity and mean net charge predicts that some (e.g. Bad and Noxa) are unstructured like Bim, whereas others are predicted to have a well-defined structure (e.g. Bik), like Bid (Figure 4a). For comparison, the prosurvival proteins, which all have a well-defined structure except for the residues that connect helices 1 and 2 in $\mathrm{Bcl}-\mathrm{x}_{\mathrm{L}}$ and $\mathrm{Bcl}-2$, were analyzed. CDF analysis was also used to discriminate between $\mathrm{BH} 3-$ only proteins that are likely to be ordered and disordered in solution (Figure 4b). Using the seven-point boundary for PONDR scores between 0.6 and 0.9 as the discriminator, ${ }^{21}$ all $\mathrm{BH} 3$-only proteins, except Bid and Bik, are predicted to be unstructured when free in solution.

To evaluate these predictive methods, we attempted to express and purify all mouse BH3-only proteins. However, many of the proteins proved difficult to express and purify. Only Bmf and Bad, minus their C-terminal $25(\mathrm{Bmf} \Delta \mathrm{C} 25)$ and $22(\mathrm{Bad} \Delta \mathrm{C} 22)$ residues respectively, could be purified to homogeneity. As observed for $\operatorname{Bim}_{\mathrm{L}} \Delta \mathrm{C} 27$, both Bmf and Bad proteins were susceptible to proteolysis during purification and eluted from sizing columns with a larger molecular mass than expected, suggestive of a disordered conformation (data not shown). In agreement with predictive methods, CD analysis of Bad and Bmf revealed a largely random coil conformation, with minima near $200 \mathrm{~nm}$, similar to that observed for Bim $\Delta \mathrm{C} 27$ (Figure $4 \mathrm{C}$ ). As predicted, based on sequence analysis and the available NMR structures, ${ }^{9,10}$ the CD spectrum for Bid was that of a primarily $\alpha$-helical protein (Figure 4c).

The presence of residual secondary structure, based on analysis of the CD spectra of Bim, Bad and Bmf, was a

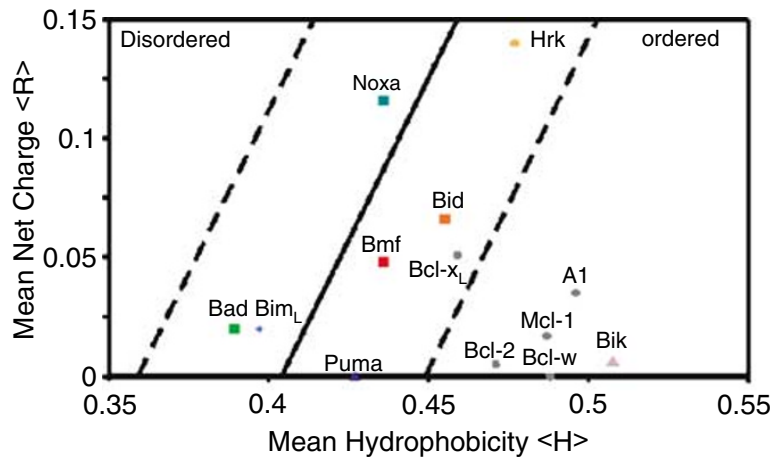

b
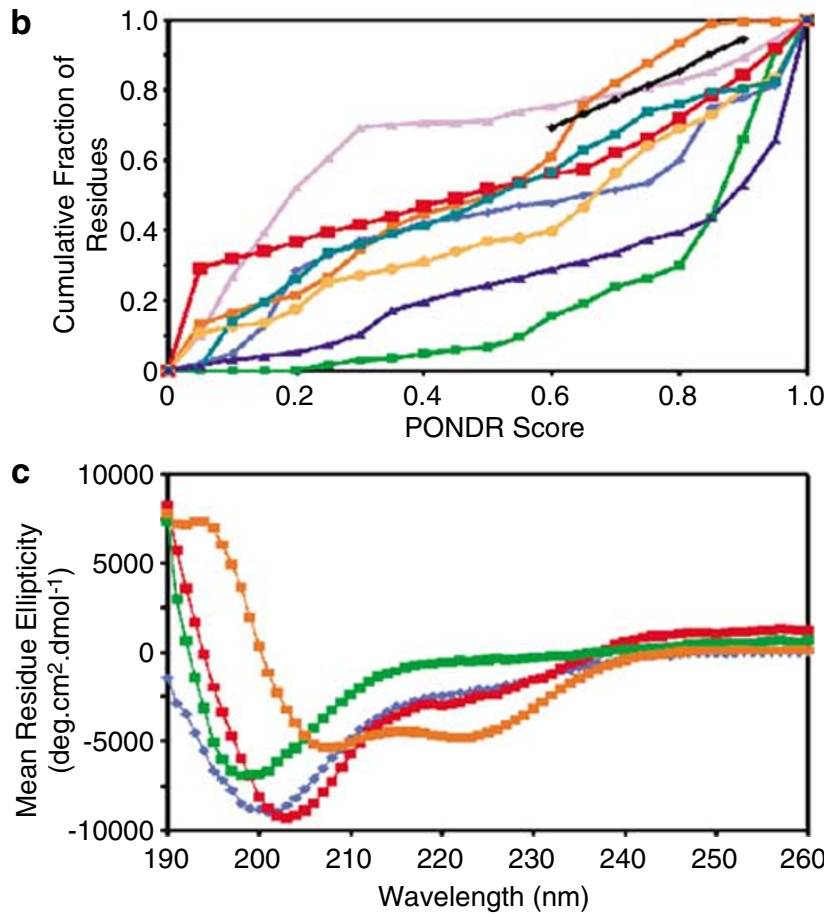

Figure 4 Some other $\mathrm{BH} 3$-only proteins are also unstructured. (a) Net charge hydrophobicity plot of all the mouse $\mathrm{BH}$-only proteins, and for reference the prosurvival Bcl-2 proteins (in gray). In the case of $\mathrm{Mcl}-1$, only the $\mathrm{BH}$ domain was analyzed. The loop that connects $\alpha 1$ and $\alpha 2$ was included in the analysis and accounts for the relative disorder seen for $\mathrm{Bcl}-\mathrm{x}_{\mathrm{L}}$. (b) CDF plots for Bim (light blue), Bmf (red), Puma (dark blue), Bid (orange), Bad (green), Bik (purple), Hrk (yellow) and Noxa (teal). The order-disorder boundary (black) is as reported. ${ }^{21}$ (c) Far UV $\mathrm{CD}$ spectra of Bid (orange), Bim ${ }_{\mathrm{L}} \Delta \mathrm{C} 27$ (light blue), $\mathrm{Bmf} \Delta \mathrm{C} 25$ (red) and $\mathrm{Bad} \Delta \mathrm{C} 22$ (green)

assessed using several algorithms as implemented at the DICHROWEB server. ${ }^{32}$ All three proteins were calculated to have a primarily random coil conformation with no significant $\alpha$-helical regions, although some residual $\beta$-structure was predicted. However, the fits were poor and sequence analysis does not indicate significant $\beta$-structure. Instead, sequence analysis of Bad and Bmf reveals regions with $\alpha$-helical propensity that are likely to be stabilized upon interaction with partner proteins such as Bcl-w, as seen for Bim.

Secondary structure characterization, based on CD spectra of four $\mathrm{BH} 3$-only proteins, therefore supports the CDFordered/disordered classification of $\mathrm{BH}$-only proteins (Figure 4b). Preliminary analysis of Noxa and Puma also 
suggests that these proteins are disordered when free in solution as they are both highly susceptible to proteolysis. In contrast, it seems highly likely that Bik, like Bid, will have a well-defined 3D structure in solution.

\section{Discussion}

IUPs have become the focus of many studies since it was recognized that a defined $3 \mathrm{D}$ structure is not a prerequisite for biological activity, indeed some proteins require the absence of 3D structure to carry out their functions. ${ }^{12}$ Such proteins are remarkably prevalent, with up to $28 \%$ of proteins encoded for by the mouse genome predicted to be intrinsically unstructured, ${ }^{21}$ and frequently involved in cell regulatory functions. ${ }^{12}$ Significantly, a recent study predicts a high level of structural disorder in human cancer-associated proteins. ${ }^{33}$ We now report that many proapoptotic $\mathrm{BH} 3-$ only proteins, which are critical regulators of apoptosis, do not have a well-defined 3D structure under physiological conditions and that they belong to the IUP family.

Protein sequence analysis predicted that Bim contained extensive regions of disorder (Figure 1). The absence of a well-defined structure was confirmed by $C D$ and NMR spectroscopy (Figure 2). Bmf and Bad also behave as unstructured proteins under physiological conditions and have CD spectra typical of IUPs (Figure 4). A more general protein sequence analysis of the eight mammalian $\mathrm{BH} 3-$ only proteins suggests that, with the exception of Bid and probably $\mathrm{Bik}$, these proteins are largely unstructured (Figure 4). This classification of Bik as a structured protein is in agreement with the phylogenetic analysis of Aouacheria et al., ${ }^{11}$ where they suggested that Bik is more closely related to Bak and therefore would be expected to have a folded structure similar to that of Bax. ${ }^{30}$

Frequently, IUPs undergo a structural transition when they bind to their targets. ${ }^{12,13}$ Comparison of the spectra for both $\mathrm{Bim}_{\mathrm{L}} \Delta \mathrm{C} 27$ and the isolated $\mathrm{BH} 3$ domain, in complex with $\mathrm{Bcl}-\mathrm{w}$, indicates that a localized conformational change accompanies interaction with prosurvival proteins (Figure 3). However, consistent with their continued sensitivity to proteolysis, the majority of residues in Bim remain unstructured in the presence of prosurvival proteins. The term molecular recognition element (MoRE) has been coined for a short disordered element of a protein that becomes ordered upon specific binding to a partner protein. ${ }^{34}$ Structural studies on peptides spanning the $\mathrm{BH} 3$-domain of $\mathrm{Bim},{ }^{6} \mathrm{Bad}^{5}$ and $\mathrm{Egl}-1^{7}$ show that they all form $\alpha$-helices when bound to prosurvival proteins, suggesting that the $\mathrm{BH} 3$ domain is an alpha helical MoRE $(\alpha-$ MoRE). The increased helicity (Figure $3 e$ ) and shifts in the presence of $\mathrm{Bcl}-\mathrm{w}$ (Figure $3 \mathrm{c}$ ) indicates that within the context of $\operatorname{Bim}_{\mathrm{L}} \Delta \mathrm{C} 27$, the $\mathrm{BH} 3$-domain also has a helical conformation similar to that seen in the $\mathrm{Bcl}-\mathrm{x}_{\mathrm{L}} / \mathrm{BimBH} 3$ peptide complex. ${ }^{6}$ Thus, the $\mathrm{BH} 3$ domain of Bim behaves as an $\alpha$-MoRE. Bim also binds a component of the dynein motor complex, DLC1, ${ }^{17}$ but only a short region of nine residues is involved in binding. ${ }^{19,35}$ Like the interaction of Bim with prosurvival $\mathrm{Bcl}-2$ proteins, there is no evidence to suggest conformational changes in Bim outside the region of direct contact with DLC1 (MG Hinds and CL Day, unpublished), rather a short $\beta$-strand is formed that extends a $\beta$-sheet within the DLC, fitting the description of a $\beta$-MoRE. ${ }^{34}$ Together, these observations suggest that Bim contains a series of linear sequence motifs, which have independent structure and function, analogous to 'beads on a string'.

It has been estimated that each $\alpha$-MoRE, such as the induced $\alpha$-helix of a $\mathrm{BH} 3$-only protein, requires fewer than 10 , and commonly only five residues to interact with its partner. ${ }^{34}$ $\mathrm{BH} 3$ domains of $\mathrm{BH} 3$-only proteins such as Bim, Bad and Bmf, are only weakly conserved motifs that in addition to three hydrophobic residues include a LXXXGDE sequence. ${ }^{11}$ As predicted for an $\alpha$-MoRE, when bound to prosurvival proteins, five residues of the $\mathrm{BH} 3$ domain, including the four conserved hydrophobic residues found on one face of an amphipathic helix, and the invariant aspartate that forms a conserved salt bridge, are the key binding determinants. Proteins containing $\alpha$-MoRE motifs are more frequently found localized to the cellular cortex and cytoskeleton ${ }^{34}$ and again, fitting this prediction, in healthy cells Bim, Bmf and Bad, are located on the microtubule-based dynein motor complex, ${ }^{17}$ Actin-based Myosin V motor complex and bound to 14-3-3 proteins, respectively. ${ }^{2}$

What triggers folding of $\mathrm{BH} 3$ domains? It seems likely that small helical segments will make the first contacts with the prosurvival protein and then additional contacts will follow resulting in propagation of structure and stable complex formation as shown by others. ${ }^{13}$ The increased $\alpha$-helicity of $\mathrm{BH} 3-$ domain peptides observed on addition of trifluoroethanol, a helix inducer, shows that the $\mathrm{BH} 3$ domains behave as nascent helices. ${ }^{8}$ However, the low abundance of hydrophobic residues in Bim, and other $\mathrm{BH} 3$-only proteins, means that while helical structure is favored by the $\mathrm{BH} 3$ domain, it is not stabilized by additional contacts and does not persist in the absence of a partner protein. Folding is therefore coupled to binding.

The functional advantages of being unstructured include decoupling of specificity from binding strength, increasing the speed of interaction and enabling proteins to interact with multiple partners. ${ }^{34}$ The eight major $\mathrm{BH} 3$-only proteins all bind at least two, and in the case of Bim and Puma interact tightly (nM affinity) with all five, mammalian prosurvival proteins. ${ }^{8}$ The hydrophobic groove to which $\mathrm{BH}$-only proteins bind is not highly conserved and the plasticity afforded by being unstructured undoubtedly contributes to their tight binding to multiple partners. When bound, approximately $1000 \AA^{2}$ of the $\mathrm{BH} 3$ domain is buried. 6,7 As observed for other unstructured proteins, small proteins/motifs can have a large interaction interface if they are disordered. If a preformed structure mediated binding, a conserved region 2-3 times larger would be expected. ${ }^{36}$ Such a short unstructured binding motif suggests that $\mathrm{BH} 3-$ only proteins will be relatively tolerant of mutations, as only mutations that specifically disrupt the binding site are likely to have a deleterious role. Consistent with this prediction, inactivating mutations of Bad have been detected in the $\mathrm{BH} 3$ domain. ${ }^{37}$ In addition, when Egl-1, the $C$. elegans $\mathrm{BH} 3-$ only protein was cloned, loss-of-function mutations occurred at a much lower frequency than predicted. ${ }^{38}$ The absence of a tertiary structure may account for the low frequency of deleterious mutations as only mutations that disrupt the $\mathrm{BH} 3$ domain or cause a frameshift error would have disrupted Egl-1 function. Typically, many loss-of- 
function mutations arise owing to disruption of the tertiary structure, but in IUPs, there is little structure to be disrupted.

BH3-only proteins are tightly controlled and a number of mechanisms keep these proteins in check, and as seen for other proteins a disordered structure offers advantages. ${ }^{16}$ For example, unstructured proteins would appear well suited to tolerate extensive splicing as seen in Bim, as fewer structural constraints are placed on the ability to insert or delete exons that modulate biological function. Phosphorylation of Bim, Bad and Bmf plays an important role in their regulation. Kinases typically bind with low affinity but high specificity, and it has been suggested that coupled folding and binding, possible when proteins are disordered, contributes to this. ${ }^{24}$ Proteosomal degradation, which regulates the levels of several $\mathrm{BH}$ only proteins, has also been shown to be more efficient for proteins with unstructured initiation sites. ${ }^{39}$ Combined, these factors point to the importance of the unstructured state in regulating the levels of the key cell killers, Bim, Bad and Bmf.

IUPs play important roles in many signaling pathways. ${ }^{12}$ Predictive methods, based on sequence analysis suggest that many of the proapoptotic BH3-only proteins belong to this class of protein and experimental evidence supports this conclusion in the case of Bim, Bad and Bmf. Further studies are required to determine the extent to which other members of this family are disordered, although both promiscuous binding and multifaceted regulation, properties of these proteins, indicate that a disordered state would be advantageous. Elucidating the nature of the structural changes associated with binding will undoubtedly contribute to our understanding of $\mathrm{BH} 3-$ only protein function, as the apparent structural simplicity of the BH3-only proteins belies their complex behavior. These studies also offer promise for the further development of small molecule inhibitors that target Bcl-2-like prosurvival proteins, as the 'induced-fit' mechanism described here suggests that different modes of binding will be accommodated.

\section{Materials and methods}

Sequence analysis. Global analysis of sequences was carried out as described previously. ${ }^{20}$ Briefly, the mean net charge of a protein was determined as the absolute value of the difference between the numbers of positively and negatively charged residues divided by the total number of residues. The mean hydrophobicity was defined as the sum of the normalized Kyte-Doolittle hydrophobicities, divided by the total number of residues minus four residues (to take account of fringe effects). These values were then plotted together with disorder-order boundary, which was defined as 〈charge $\rangle=2.743$ $\left\langle\right.$ hydrophobicity > -1.109 , and the 0.045 boundaries. $^{20,21}$ Disordered proteins are accurately (95\%) predicted if outside the 0.045 boundary whereas $76 \%$ of disordered proteins are accurately predicted with no boundary. ${ }^{21}$ Sequences were also analyzed using a series of neural network predictors, which use amino-acid sequence data to predict disorder, as implemented in PONDR VL-XT ${ }^{\mathbb{R}}$ (http:// www.pondr.com). The optimal boundary was used as the discriminator for ordered and disordered proteins. ${ }^{21}$ The probability of sequences having regions of localized order and disorder was determined using DisEMBL, as implemented via the web interface (http://dis.embl.de). ${ }^{23}$ PEST sequences were found using PESTfind (https://emb1.bcc.univie.ac.at/toolbox/pestfind/pestfind-analysis-webtool.htm).

Overexpression and purification of proteins. Mouse Bmf (accession number: AAK38747), Bad (NP_031548), Bim $($ AAC40030), truncated at the Cterminus by 25,22 and 27 residues, respectively; full-length mouse Bid (AAC71064) and human Bcl-w (Q92843), either truncated by 10 or 37 residues, were expressed as glutathione-S-transferase (GST) fusion proteins in E. coli BL21(DE3) and purified as described previously. ${ }^{30,35,40}$ Following release from GST using PreScission protease, all purified proteins have five additional $\mathrm{N}$-terminal residues, GPLGS, as a result of cloning. Isotopically, labeled proteins were expressed as described previously. ${ }^{30,40}$ The $\mathrm{BH} 3$ domain of Bim (BimBH3) was made using the $\mathrm{pET}-31 \mathrm{~b}$ expression vector (Novagen). Briefly, oligonucleotides that encoded the peptide (sequence DLRPEIRIAQELRRIGDEFNETYTRR) were annealed and cloned into AlwN1 digested and phosphatased vector, a recombinant plasmid that contained one copy of the oligonucleotide sequence was selected and used for expression. The fusion protein was expressed and the peptide purified as described by the suppliers (Novagen) except that following cyanogen bromide digestion and dialysis, the soluble peptide was purified from the histidine tag using reverse phase chromatography on a $3 \mathrm{ml}$ Resource RPC column (acetonitrile gradient from 28 to $37 \%$ for peptide elution). Any remaining histidine-tagged material was removed by passage though another $\mathrm{Ni}^{2+}$ column. Mass spectrometry was used to confirm peptide homogeneity.

Analytical centrifugation. Sedimentation velocity data were acquired using an Optima XL-A analytical ultracentrifuge (Beckman Coulter) equipped with an AnTi60 rotor. The sample and reference sectors were filled with $380 \mu \mathrm{l} \mathrm{Bim} L \mathrm{C} 27$ $(0.8 \mathrm{mg} / \mathrm{ml}$ in phosphate-buffered saline (PBS) pH 7.4) and $400 \mu \mathrm{l}$ PBS pH 7.4, respectively. Centrifugation was carried out at $20^{\circ} \mathrm{C}$ and 50000 r.p.m. The absorbance of the sample at $235 \mathrm{~nm}$ (relative to the reference) was recorded at $0.001 \mathrm{~cm}$ increments across the cell at $5 \mathrm{~min}$ intervals for $5.7 \mathrm{~h}$, yielding a data set of 70 radial scans.

The sedimentation of $\operatorname{Bim}_{\llcorner} \Delta C 27$ was modeled as a single class of noninteracting solute under ideal solution conditions. Data were analyzed by nonlinear regression using the program Sedfit. ${ }^{41}$ Scans $15-50$ were included in the analysis, as they exhibited unequivocal evidence of a solute boundary and plateau. The buffer density $(\rho)$ and partial specific volume of $\operatorname{Bim}_{\llcorner} \Delta C 27(\bar{V})$ at $20^{\circ} \mathrm{C}$ were calculated as $1.0045 \mathrm{~g} / \mathrm{ml}$ and $0.7095 \mathrm{ml} / \mathrm{g}$, respectively, using the program Sednterp. During the fit, the loading absorbance $(c)$, relative molecular mass $\left(M_{\mathrm{r}}\right)$ and sedimentation coefficient $(S)$ of Bim $\llcorner\Delta C 27$ were optimized for best fit to the Lamm equation. In addition, time-independent noise (analogous to the baseline) was iteratively separated from the data.

CD spectroscopy. CD experiments were recorded on an Olis spectropolarimeter equipped with a Peltier type temperature controller. All scans were recorded at $25^{\circ} \mathrm{C}$ with protein concentrations in the range of $10-50 \mu \mathrm{M}$ in $5 \mathrm{mM}$ sodium phosphate pH 6.7 except where noted. Spectra were recorded in either 1 or $2 \mathrm{~mm}$ pathlength cuvettes, using a $1 \mathrm{~nm}$ step resolution and $3 \mathrm{~s}$ integration time. Three scans were averaged for each run and appropriate baselines were subtracted. For analysis of the conformational change associated with Bim/Bcl-w complex formation, a $10 \mathrm{~mm}$ path length split cuvette was used. Spectra were acquired, before and after mixing by inversion, using the same conditions as above. All CD signals were converted to mean residue ellipticity and have the units, $\operatorname{deg} \cdot \mathrm{cm}^{2} / \mathrm{dmol}$.

Size exclusion chromatography and immunoblotting. Purified proteins were separated on a $20 \mathrm{ml}$ Superdex S200 column (GE Healthcare) that had been equilibrated in PBS $\left(140 \mathrm{mM} \mathrm{NaCl}, 2.7 \mathrm{mM} \mathrm{KCl}, 10 \mathrm{mM} \mathrm{Na}_{2} \mathrm{HPO}_{4}\right.$, $1.8 \mathrm{mM} \mathrm{KH}_{2} \mathrm{PO}_{4}, \mathrm{pH} 7.4,0.02 \% \mathrm{NaN}_{3}$ ). Fractions, $500 \mu \mathrm{l}$ in volume, were collected and then analyzed by SDS-PAGE followed by immunoblotting. Proteins were detected using rat monoclonal anti-Bim (3C5) or anti-Bcl-w (13F9) and HRPconjugated goat anti-rat (SouthernBiotech). Protein sizes were estimated by comparison with a range of standard proteins that had been separated under the same conditions.

NMR spectroscopy. ${ }^{1} \mathrm{H}-{ }^{15} \mathrm{~N}-\mathrm{HSQC}$ spectra were recorded at $25^{\circ} \mathrm{C}$ on a Bruker DRX-600 spectrometer equipped with triple resonance probes and pulsed field gradients. Samples used for NMR contained $\sim 0.5 \mathrm{mM}$ protein in $50 \mathrm{mM}$ sodium phosphate ( $\mathrm{pH} 6.7), 70 \mathrm{mM} \mathrm{NaCl}, 2 \mathrm{mM}$ TCEP and $0.04 \%$ sodium azide in $\mathrm{H}_{2} \mathrm{O}^{2}{ }^{2} \mathrm{H}_{2} \mathrm{O}(95: 5)$. For analysis of the complexes, excess unlabeled $\mathrm{Bcl}-\mathrm{w} \Delta \mathrm{C} 10$ $(\mathrm{A} 128 \mathrm{E})^{30}$ was added to ${ }^{15} \mathrm{~N}$-labeled $\mathrm{Bim} \mathrm{L} \Delta \mathrm{C} 27$ and $\mathrm{BimBH} 3$ samples.

Limited proteolysis and mass spectrometry. Purified $\operatorname{Bim}_{\mathrm{L}} \Delta \mathrm{C} 27$ alone $(\sim 26 \mu \mathrm{g})$, Bcl-w $\Delta \mathrm{C} 10$ alone $(40 \mu \mathrm{g})$ and mixtures of the two proteins were subjected to digestion with trypsin $(70 \mathrm{ng})$ in a total volume of $130 \mu$. Digests were incubated at room temperature. Samples taken at the indicated time points were treated with formic acid and rapidly heat inactivated. The products were evaluated by gel electrophoresis. Before mass spectrometry, peptides were purified using a Sep-pak reverse phase cartridge. 


\section{Acknowledgements}

We thank Bronwyn Carlisle for help with preparing the figures. Our research is supported by the Marsden Fund (NZ), Leukemia and Lymphoma Society (Specialized Centre for Research 7015-02), Australian NH\&MRC (Program Grant 257502) and fellowship (DCSH) and US NCl (CA 80188).

1. Cory S, Huang DC, Adams JM. The Bcl-2 family: roles in cell survival and oncogenesis. Oncogene 2003; 22: 8590-8607.

2. Puthalakath $\mathrm{H}$, Strasser A. Keeping killers on a tight leash: transcriptional and posttranslational control of the pro-apoptotic activity of BH3-only proteins. Cell Death Differ 2002; 9: 505-512.

3. Hinds MG, Day CL. Regulation of apoptosis: uncovering the binding determinants. Curr Opin Struct Biol 2005; 15: 690-699.

4. Sattler M, Liang H, Nettesheim D, Meadows RP, Harlan JE, Eberstadt M et al. Structure of Bcl-x $\mathrm{X}_{\mathrm{L}}$-Bak peptide complex: recognition between regulators of apoptosis. Science 1997; 275: 983-986

5. Petros AM, Nettesheim DG, Wang Y, Olejniczak ET, Meadows RP, Mack J et al. Rationale for $\mathrm{Bcl}-\mathrm{x}_{\mathrm{L}} / \mathrm{Bad}$ peptide complex formation from structure, mutagenesis, and biophysical studies. Protein Sci 2000; 9: 2528-2534

6. Liu X, Dai S, Zhu Y, Marrack P, Kappler JW. The structure of a Bcl-x/Bim fragment complex: implications for Bim function. Immunity 2003; 19: 341-352.

7. Yan N, Gu L, Kokel D, Chai J, Li W, Han A et al. Structural, biochemical, and functional analyses of CED-9 recognition by the proapoptotic proteins EGL-1 and CED-4. Mol Cell 2004; 15: 999-1006.

8. Chen L, Willis SN, Wei A, Smith BJ, Fletcher Jl, Hinds MG et al. Differential targeting of prosurvival $\mathrm{Bcl}-2$ proteins by their $\mathrm{BH}$-only ligands allows complementary apoptotic function. Mol Cell 2005; 17: 393-403.

9. McDonnell JM, Fushman D, Milliman CL, Korsmeyer SJ, Cowburn D. Solution structure of the proapoptotic molecule BID: a structural basis for apoptotic agonists and antagonists. Cell 1999; 96: 625-634.

10. Chou JJ, Li H, Salvesen GS, Yuan J, Wagner G. Solution structure of BID, an intracellular amplifier of apoptotic signaling. Cell 1999; 96: 615-624.

11. Aouacheria $A, B$ Bunet $F$, Gouy M. Phylogenomics of life-or-death switches in multicellular animals: Bcl-2, BH3-only and BNIP families of apoptotic regulators. Mol Biol Evol 2005; 22: 2395-2416.

12. Dyson $\mathrm{HJ}$, Wright $\mathrm{PE}$. Intrinsically unstructured proteins and their functions. Nat Rev Mol Cell Biol 2005; 6: 197-208.

13. Dunker AK, Cortese MS, Romero P, lakoucheva LM, Uversky VN. Flexible nets. The roles of intrinsic disorder in protein interaction networks. FEBS J 2005; 272: 5129-5148.

14. Adachi M, Zhao X, Imai K. Nomenclature of dynein light chain-linked BH3-only protein Bim isoforms. Cell Death Differ 2005; 12: 192-193.

15. O'Connor L, Strasser A, O'Reilly LA, Hausmann G, Adams JM, Cory S et al. Bim: A novel member of the Bcl-2 family that promotes apoptosis. EMBO J 1998; 17: 384-395.

16. Ley R, Ewings KE, Hadfield K, Cook SJ. Regulatory phosphorylation of Bim: sorting out the ERK from the JNK. Cell Death Differ 2005; 12: 1008-1014.

17. Puthalakath H, Huang DC, O'Reilly LA, King SM, Strasser A. The proapoptotic activity of the Bcl-2 family member Bim is regulated by interaction with the dynein motor complex. Mol Cell 1999; 3: 287-296.

18. Akiyama T, Bouillet P, Miyazaki T, Kadono Y, Chikuda H, Chung Ul et al. Regulation of osteoclast apoptosis by ubiquitylation of proapoptotic BH3-only Bcl-2 family member Bim. EMBO J 2003; 22: 6653-6664.

19. Fan J, Zhang Q, Tochio H, Li M, Zhang M. Structural basis of diverse sequence-dependent target recognition by the 8 kda dynein light chain. J Mol Biol 2001; 306: 97-108.
20. Uversky VN, Gillespie JR, Fink AL. Why are 'natively unfolded' proteins unstructured under physiologic conditions? Proteins 2000; 41: 415-427.

21. Oldfield CJ, Cheng Y, Cortese MS, Brown CJ, Uversky VN, Dunker AK. Comparing and combining predictors of mostly disordered proteins. Biochemistry 2005; 44: 1989-2000.

22. Oldfield CJ, Ulrich EL, Cheng Y, Dunker AK, Markley JL. Addressing the intrinsic disorder bottleneck in structural proteomics. Proteins 2005; 59: 444-453.

23. Linding R, Jensen LJ, Diella F, Bork P, Gibson TJ, Russell RB. Protein disorder prediction: implications for structural proteomics. Structure 2003; 11: 1453-1459.

24. lakoucheva LM, Radivojac P, Brown CJ, O'Connor TR, Sikes JG, Obradovic Z et al. The importance of intrinsic disorder for protein phosphorylation. Nucleic Acids Res 2004; 32 1037-1049.

25. Singh GP, Ganapathi M, Sandhu KS, Dash D. Intrinsic unstructuredness and abundance of PEST motifs in eukaryotic proteomes. Proteins 2006; 62: 309-315.

26. Bourhis JM, Johansson K, Receveur-Brechot V, Oldfield CJ, Dunker KA, Canard B et al. The C-terminal domain of measles virus nucleoprotein belongs to the class of intrinsically disordered proteins that fold upon binding to their physiological partner. Virus Res 2004 99: 157-167.

27. Bienkiewicz EA, Adkins JN, Lumb KJ. Functional consequences of preorganized helica structure in the intrinsically disordered cell-cycle inhibitor p27(KIP1). Biochemistry 2002 41: $752-759$

28. Dyson $\mathrm{HJ}$, Wright PE. Insights into the structure and dynamics of unfolded proteins from nuclear magnetic resonance. Adv Protein Chem 2002; 62: 311-340.

29. Wilson-Annan J, O'Reilly LA, Crawford SA, Hausmann G, Beaumont JG, Parma LP et al. Proapoptotic $\mathrm{BH} 3-$ only proteins trigger membrane integration of prosurvival $\mathrm{Bcl}-\mathrm{W}$ and neutralize its activity. J Cell Biol 2003; 162: 877-887.

30. Hinds MG, Lackmann M, Skea GL, Harrison PJ, Huang DC, Day CL. The structure of Bcl-w reveals a role for the $\mathrm{C}$-terminal residues in modulating biological activity. EMBO J 2003 22: $1497-1507$.

31. Denisov AY, Chen G, Sprules T, Moldoveanu T, Beauparlant P, Gehring K. Structura model of the Bcl-w-Bid peptide complex and its interactions with phospholipid micelles. Biochemistry 2006; 45: 2250-2256.

32. Whitmore L, Wallace BA. DICHROWEB, an online server for protein secondary structure analyses from circular dichroism spectroscopic data. Nucleic Acids Res 2004 32: W668-W673.

33. lakoucheva LM, Brown CJ, Lawson JD, Obradovic Z, Dunker AK. Intrinsic disorder in cellsignaling and cancer-associated proteins. J Mol Biol 2002; 323: 573-584.

34. Oldfield CJ, Cheng Y, Cortese MS, Romero P, Uversky VN, Dunker AK. Coupled folding and binding with alpha-helix-forming molecular recognition elements. Biochemistry 2005 44: 12454-12470.

35. Day CL, Puthalakath H, Skea G, Strasser A, Barsukov I, Lian LY et al. Localization of dynein light chains 1 and 2 and their pro-apoptotic ligands. Biochem J 2004; 377: 597-605.

36. Gunasekaran K, Tsai CJ, Kumar S, Zanuy D, Nussinov R. Extended disordered proteins: targeting function with less scaffold. Trends Biochem Sci 2003; 28: 81-85.

37. Lee JW, Soung YH, Kim SY, Nam SW, Kim CJ, Cho YG et al. Inactivating mutations of proapoptotic Bad gene in human colon cancers. Carcinogenesis 2004; 25: 1371-1376.

38. Conradt B, Horvitz HR. The C. elegans protein EGL-1 is required for programmed cell death and interacts with the Bcl-2-like protein CED-9. Cell 1998; 93: 519-529.

39. Prakash S, Tian L, Ratliff KS, Lehotzky RE, Matouschek A. An unstructured initiation site is required for efficient proteasome-mediated degradation. Nat Struct Mol Biol 2004 11: 830-837.

40. Day CL, Chen L, Richardson SJ, Harrison PJ, Huang DC, Hinds MG. Solution structure of prosurvival Mcl-1 and characterization of its binding by proapoptotic BH3-only ligands. J Biol Chem 2005; 280: 4738-4744.

41. Schuck P. Size-distribution analysis of macromolecules by sedimentation velocity ultracentrifugation and lamm equation modeling. Biophys J 2000; 78: 1606-1619. 